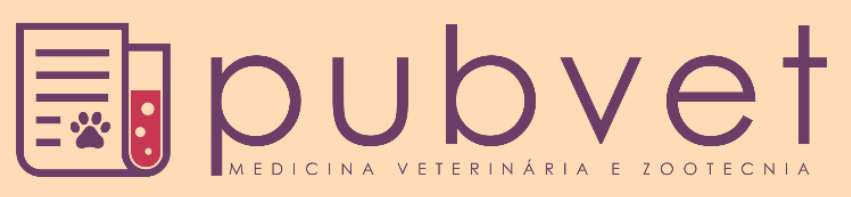

https://doi.org/10.31533/pubvet.v13n7a364.1-10

\title{
Emprego do cateter ureteral duplo J em complicações por cálculos
}

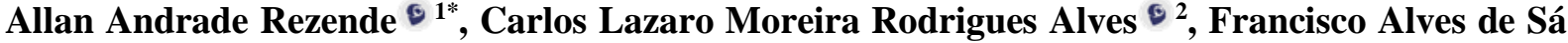 \\ Neto $^{3}$, Luciana Correia De Oliveira ${ }^{4}$, Carlos Henrique Souza Santos ${ }^{2}$, Carlos Alberto Palmeira \\ Sarmento $^{2} \bullet$, Rachel Livingstone Felizola Soares De Andrade ${ }^{5} \bullet$, Maria Carolina Cardoso ${ }^{2}$
}

${ }^{I}$ Faculdade Pio Decimo

${ }^{2}$ Clinica veterinária ATRIUM

${ }^{3}$ Medico Veterinário Autônomo

${ }^{4}$ Hospital Veterinário Dr. Vicente Borelli

${ }^{5}$ PatLab

*Autor para correspondência, E-mail: allan_a.rezende@hotmail.com

Resumo. A urolitíase é uma afecção do trato urinário provocada pela presença de cálculos, em qualquer segmento do trato urinário, que decorre da interação de vários fatores predisponentes desencadeados pela precipitação de certos metabólitos na urina. A disposição de cateteres uretrais é realizada com maior frequência para o tratamento de obstrução ureteral, e a forma mais frequente é o cateter ureteral duplo J. O presente trabalho objetivou descrever um caso de urolitíase recorrente em uma cadela da raça Bichon Frisé com 9 anos de idade e histórico de sobre peso, poliúria, polidipsia, polifagia, e infecções urinárias recorrentes, com presença de urólitos vesicais e renais. Ao final do tratamento constatou-se a ausência destes por meio de exame ultrassonográfico e assim, tal caso evidencia a eficácia e importância do emprego do mesmo em complicações por cálculos.

Palavras-chave: afecções, cirurgia, terapêutica, urolitíase

\section{Use of catheter dual J in ureteral complications by calculations}

Summary. Urolithiasis is a condition of the urinary tract caused by the presence of uroliths in any segment of the urinary tract resulting from the interaction of several predisposing factors triggered by the precipitation of metabolites in the urine. The provision of urethral stents is most frequently performed for the treatment of urethral obstruction, and the most frequent form is the retrouretropic catheter. The present study aimed to describe a case of recurrent urolithiasis in a Bichon Frisé 9 - year - old female with a history of weight, polyuria, polydipsia, polyphagia, and recurrent urinary infections with bladder and renal uroliths. At the end of the treatment the absence of these was verified by means of ultrasonographic examination and thus, this case shows the efficacy and importance of the use of the same in complications by calculations.

Key words: disorders, surgery, therapy, urolithiasis

\section{Uso del catéter ureteral doble J en complicaciones por cálculos}

Resumen. La urolitiasis es una afección del tracto urinario provocada por la presencia de urólitos, en cualquier segmento del tracto urinario, que deriva de la interacción de varios factores predisponentes desencadenados por la precipitación de metabolitos en la orina. La disposición de stents uretrales se realiza con mayor frecuencia para el tratamiento de obstrucción uretral, y la forma más frecuente es el catéter doble J. El presente trabajo objetivó describir un caso de urolitiasis recurrente en una perra de la raza Bichon Frisé con 9 años e histórico de sobre peso, poliuria, polidipsia, polifagia, e infecciones urinarias 
recurrentes, con presencia de urólitos vesicales y renales. Al final del tratamiento se constató la ausencia de éstos por medio de examen ultrasonográfico y así, tal caso evidencia la eficacia e importancia de este catéter en complicaciones por cálculos.

Palabras clave: afecciones, cirugía, terapéutica, urolitiasis

\section{Introdução}

A urina dos cães é uma complexa solução composta por sais como fosfato amoníaco magnesiano e oxalato de cálcio. Os quais podem permanecer em condições de repleção e reverter a urina a supersaturação. Assim, desencadear a precipitação ou a capacidade de formar cristais a partir dos sais dissolvidos em excesso (Brustolin, 2017). Essa supersaturação é influenciada por três fatores: (1) o aumento do grau de excreção urinária dos minerais, (2) redução de inibidores de cristalização na urina e (3) o pH urinário (Kate et al., 2015).

A urolitíase é um termo que se refere à presença de urólitos, em qualquer segmento do trato urinário. Decorre da interação de vários fatores predisponentes adquiridos, congênitos e familiares, que levam a precipitação de metabólitos na urina (Osborne et al., 2009). A urolitíase é uma afecção bastante comum na clínica de pequenos animais, sendo a terceira doença mais comum do trato urinário dos cães (Grimes et al., 2018). Afeta de $1,5 \%$ a 3,0\% de todos os cães admitidos em clínicas veterinárias e mais de $25 \%$ dos gatos com doença do trato urinário inferior (Keihani et al., 2018). Cerca de 95\% dos urólitos localiza-se na uretra ou bexiga, dentre estes, os mais comuns são os de fosfato amônio magnesiano (estruvita) e oxalato de cálcio, os de urato, cistina, sílica e xantina são considerados os mais infrequentes (Choo et al., 2018). Os animais geralmente apresentam sinais de cistite, hematúria, polaquiúria e estrangúria, podendo, no entanto, apresentarem-se assintomáticos (Choo et al., 2018).

O diagnóstico de urolitíase envolve o histórico do paciente, exame físico, achados laboratoriais e exames de imagem. Exames de urinálise, cultura urinária, radiografia e ultrassonografia tornam-se necessários para diferenciar os urólitos de infecções do trato urinário, neoplasias, pólipos, coágulos sanguíneos e anomalias congênitas urogenitais (Mariano et al., 2018). A presença de atividade metabólica é de relevância prognóstica e terapêutica. Urólitos em pacientes assintomáticos sem bacteriúria podem ser apenas monitorados quanto à presença de atividade ou não. Em caso de se tornarem ativos, pode-se optar pela instauração de terapia médica ou cirúrgica (Nicoli et al., 2012).

A intervenção precoce com procedimentos cirúrgicos ou minimamente invasivos é indicada para manter um rim funcional. A colocação cateteres ureterais duplos $\mathrm{J}$ tem sido realizada com maior frequência para o tratamento de obstrução ureteral (Grimes et al., 2018). É importante lembrar que, animais com histórico de urolitíase tem uma grande chance de desenvolver recorrência (Picavet et al., 2007).

Este trabalho tem como objetivo relatar um caso de cálculo recorrente em um cão da raça Bichon Frise e ressaltar a importância do emprego do cateter ureteral duplo J em complicações ureterais.

\section{Material e métodos}

Foi atendido, na Clínica Veterinária Atrium Especialidades Veterinária, na cidade de Aracaju Sergipe, uma cadela, da raça Bichon Frisé, com 11 anos de idade, de pelagem branca e peso 14,6 kg. O animal apresentava sobrepeso, poliúria, polidipsia e polifagia, possuía histórico de infecções urinárias recorrentes, com presença de urólitos vesicais e renais. No exame clínico, foram observadas frequência cardíaca de $120 \mathrm{bpm}$, pressão artéria sistólica $180 \mathrm{mmHg}$ e glicemia $112 \mathrm{mg} / \mathrm{dl}$. E solicitados, como exames complementares: hemograma, bioquímico sérica, ultrassonografia abdominal e teste de estimulação.

Após o decorrer do tratamento, a paciente retorna a clínica com o quadro de apatia e fortes dores a palpação abdominal. Foi solicitada urinálise (Tabela 1) e exame radiográfico (Figura 1), o qual comprovou presença de litíases em região de ureter proximal ao rim e vesícula urinaria.

De acordo com o quadro do paciente, o mesmo foi encaminhado para cirurgia para retirada de urólitos vesicais e implementação do cateter duplo J para reestabelecimento do fluxo urinário do rim para a vesícula urinária. 
Tabela 1. Exame de urina de uma cadela da raça bichon frisé, de 11 anos de idade e 14,6 kg. Ao exame físico: Amostra de Urina com $6 \mathrm{ml}$ de aspecto turvo, cor amarelo claro e densidade 1.024. Exame químico: pH: 9,0, presença de traços proteicos, ausência de glicose, corpos cetonicos e sangue. Exame de sedimento: > 50 hemácias e $>5$ leucócitos por campo, presença de celuraridade de etiologia epitelial renal - tubular renal, cilindros hemáticos e ausência de cristais e, por fim, observadas presença de muco e bactérias.

\begin{tabular}{lcc}
\hline Exame físico & Resultados & Valores de referência \\
\hline Volume & $6 \mathrm{ml}$ & Variável \\
Aspecto & Turvo & Límpido \\
Cor & Amarelo claro & Amarelo claro a escuro \\
Densidade & 1.024 & $1.015-1.045$ \\
\hline Exame químico & & $4,5-8,5$ \\
\hline pH & 9,0 & Ausentes \\
Proteínas & Traços & Ausentes \\
Glicose & Ausente & Ausentes \\
C. Cetônicos & Ausentes & Ausentes \\
Sangue oculto & $* *$ & $0-3 /$ campo \\
\hline Exame de sedimento & & $0-3 /$ campo \\
\hline Hemácias & $>50 /$ campo & Ocasionais \\
Leucócitos & $5 /$ campo & Cilindro hialino \\
Células & Epitelial renal; tubular renal & Ausentes \\
Cilindros & Cilindro hemático & \\
Cristais & Ausentes & Presença de bactérias e muco \\
\hline Observações & &
\end{tabular}



Figura 1. Exame radiográfico, o qual apresenta presença de estruturas radiopacas difusas em regiões de ureter proximal e vesícula urinaria sugestiva presença de calculosureterais.

Com protocolo anestésico, realizou-se a medicação pré-anestésica com morfina ${ }^{\mathrm{a}}(0,5 \mathrm{mg} / \mathrm{kg}$ intramuscular). Para a indução foi utilizado $\operatorname{propofol}^{\mathrm{b}}(6 \mathrm{mg} / \mathrm{kg}$ endovenosa), com respeito da dose e efeito, seguida de intubação traqueal. E manutenção por meio de anestesia inalatória com Isoflurano ${ }^{c}$.

Com o paciente em decúbito dorsal realizou-se uma incisão ventral mediana na pele, iniciou-se próximo da região do umbigo com sequência ao púbis. Fora incisa, com o bisturi, no tecido subcutâneo até a fáscia externa do musculo reto do abdome. Ligaram-se os pequenos sangramentos subcutâneos e identificou-se a linha alba. A parede abdominal foi elevada para incisão em linha alba com o mesmo bisturi. Utilizou-se uma tesoura para estender a incisão crânio-caudalmente até aproximar da extensão da incisão da pele. Identificou e isolou a vesícula urinaria da cavidade abdominal, e dispô-la gases umedecidos abaixo da mesma. Suturas foram feitas no ápice da vesícula urinaria e trígono para facilitar 
sua manipulação. Realizou-se uma incisão na parte dorsal da vesícula urinaria, ao lado dos ureteres e entre os maiores vasos sanguíneos. Removeu-se a urina por sucção. Com a vesícula urinaria exposta retirou-se os urólitos vesicais e encaminhados para análise. Em seguida, fora introduzido via óstio uretral o guia e o cateter duplo J pelo ureter até a pelve renal. Após o procedimento fora realizada completa rafia das partes e estruturas teciduais até a disposição completa ao término do procedimento.

Demostrou-se, pela análise do urólito sua composição se fundamentada em $90 \%$ de fosfato amônia magnesiano hexahidratado, $10 \%$ fosfato de cálcio carbonato, traços oxalato de cálcio monohidratado e traços matriz orgânica amorfa (Figura 2).

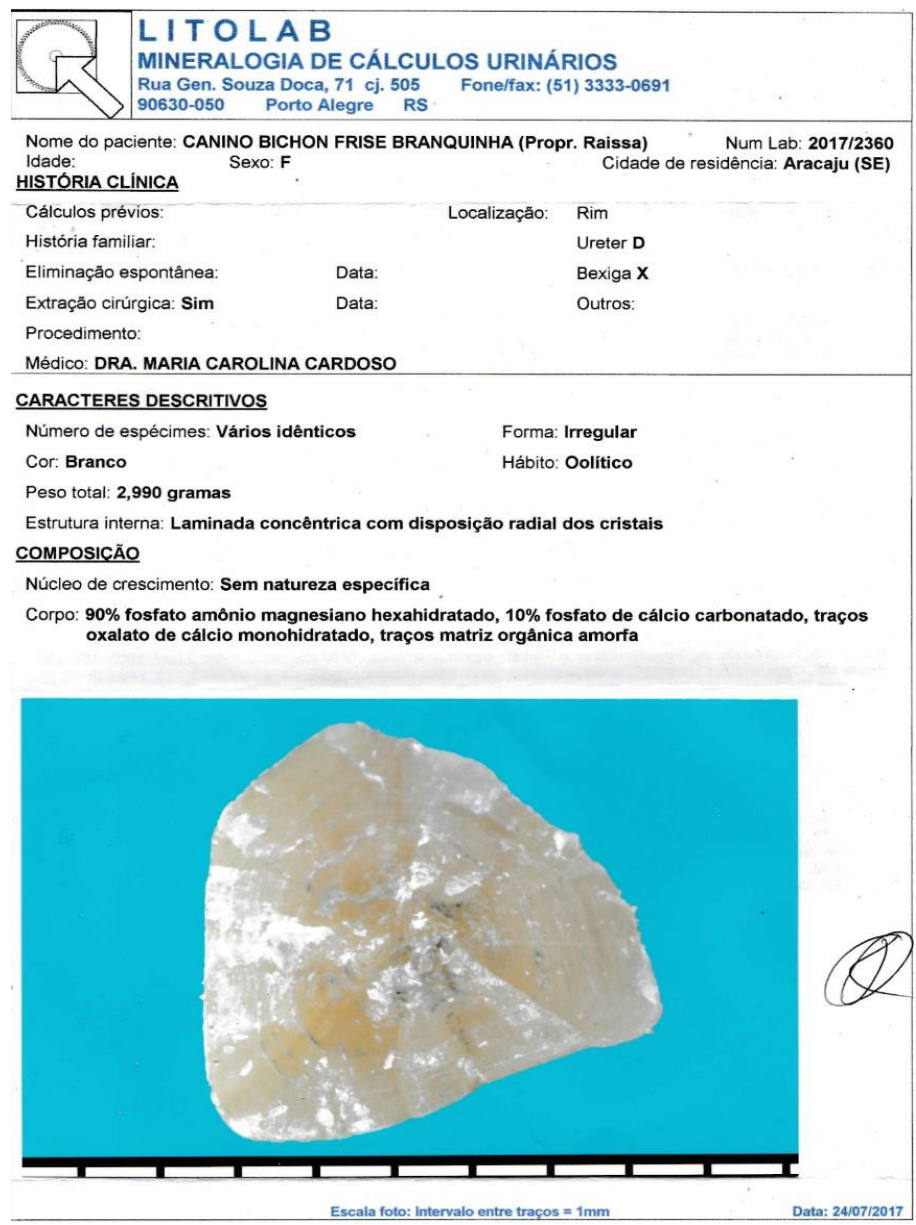

Figura 2. Imagem do urólito de uma cadela da raça Bichon frisé, de 11 anos de idade e 14,6 kg. A amostra apresentava vários fragmentos idênticos de forma irregular de cor branca de hálito oolítico com peso total 2,990 gramas e estrutura interna de lâmina concêntrica com disposição radial dos cristais, composta de $90 \%$ de fosfato amônio magnesiano hexahidratado, $10 \%$ fosfato de cálcio carbonatado, traços oxalato de cálcio monohidratado, traços de matriz orgânica amorfa. Sem natureza específica.

\section{Resultados e discussão}

No hemograma não se observou qualquer alteração, já na bioquímica sérica, contatou-se variação na fosfatase alcalina de $1052 \mathrm{UI} / \mathrm{L}(10$ - $96 \mathrm{UI} / \mathrm{L})$; triglicerídeos $869 \mathrm{mg} / \mathrm{dl}(20-112 \mathrm{mg} / \mathrm{dl})$, e colesterol de $452 \mathrm{mg} / \mathrm{dl}(135-270 \mathrm{mg} / \mathrm{dl})$. Iniciou-se o tratamento com bezafibrato ${ }^{\mathrm{d}}$ por duas vezes ao dia, manejo da dieta alimentar de 107,8 gramas (65\%) de batata doce/ inhame/ macaxeira cozida, 38,1 gramas (7\%) de carne moída/peito de frango, 9,9 gramas (5\%) de aveia em flocos, 41,3 gramas (16\%) de cenoura cozida, 1 grama $(0,7 \%)$ de farinha de casca de osso, 1 comprimido de complexo vitamínico ${ }^{\mathrm{e}}, 1$ grama $(0,4 \%)$ de sal Light e $12,9 \mathrm{ml}$ de óleo de soja. Dieta descrita de quantidades diárias fracionada em 3 a 6 refeições durante 4 semanas. (Tabela 2) e suplementação com ômega $3^{\mathrm{f}}$.

Com os resultados dos exames de ultrassonografia abdominal não foi possível individualizar a glândula adrenal, devido à sensibilidade dolorosa do paciente em topografia renal e o teste de estimulação $(22,6)$ foi diagnosticado hiperadrenocorticismo. 
Tabela 2. Dieta alimentar prescrita para a cadela da raça Bichon frisé, de 11 anos de idade e 14,6 kg

\begin{tabular}{lll}
\hline Peso & $10,2 \mathrm{~kg}$ & \\
NEM & $542,2 \mathrm{kcal}$ & \\
EM & $2,10 \mathrm{kcal} / \mathrm{g}$ & Quantidade \\
Quantidade Total & $214,8 \mathrm{~g} / \mathrm{dia}$ & 11,2 col. sopa \\
\hline Ingredientes & $107,8 \mathrm{~g}$ & 1,2 col. sopa \\
\hline Batata doce/inhame & $38,1 \mathrm{~g}$ & 0,9 col. sopa \\
Carne moída bov/frango & $9,9 \mathrm{~g}$ & 2,1 col. sopa \\
Aveia em flocos & $41,3 \mathrm{~g}$ & 1,2 col. chá \\
Cenoura cozida & $1,8 \mathrm{~g}$ & 0,3 col. chá \\
Levedura de cerveja & $1,0 \mathrm{~g}$ & 0,4 col. chá \\
Farinha de casca de ovo & $1 \mathrm{comp}$. & 2,2 col. sopa \\
Centrum & \\
Sal Light & $1,0 \mathrm{~g}$ & $12,9 \mathrm{ml}$ \\
Óleo de soja & &
\end{tabular}

No exame ultrassonográfico foi observado as seguintes alterações: Vesícula biliar repleta por líquido anecogênico e ecogênico (lama), no lúmen (Figura 3).

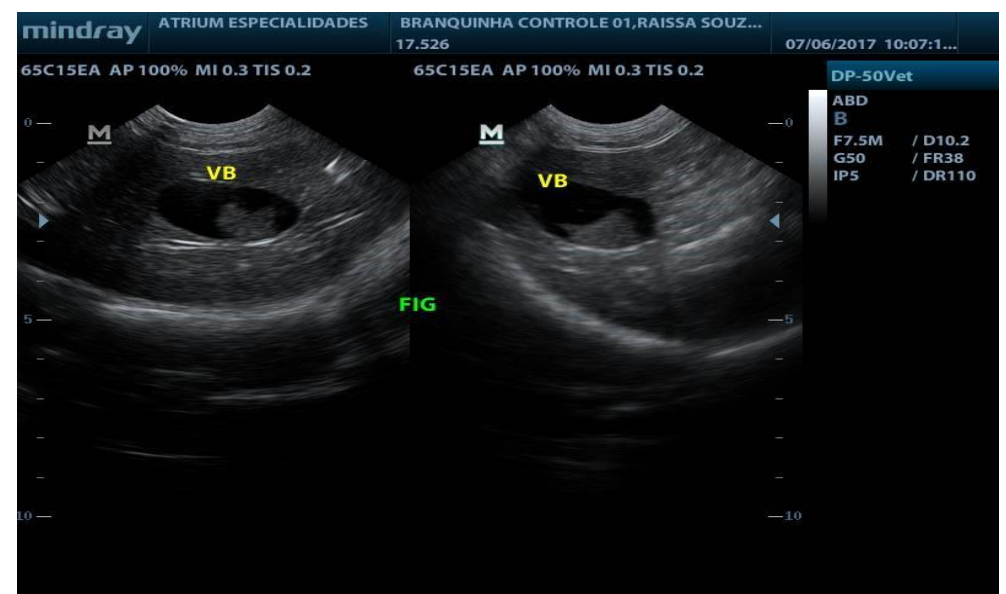

Figura 3. Exame ultrassonográfico realizado em uma cadela da raça Bichon frisé, de 11 anos de idade e 14,6 kg. Observa-se vesícula biliar repleta por líquido anecogênico e também hipoecogênico (lama), no lúmen.

O rim direito com manutenção da relação cortical-medular e arquitetura interna pouco definida devido à dilatação pélvica por conteúdo anecogênico, possivelmente relacionado à hidronefrose leve ou processo inflamatório. Visibilizou-se dilatação ureteral proximal, identificado a presença de pelo menos duas imagens, com forma arredondada, bordas delimitadas, hiperecogênica e formadora de sombreamento acústico posterior, localizadas topograficamente ao nível ureter proximal, imagens ultrassonográficas que podem estar relacionadas com hidroureter e litíases ureterais (Figura 4A e B).

A vesícula urinaria apresentava-se com paredes espessadas e pouco regulares, notou-se a presença de imagens, com forma ovalada, bordas delimitadas, hiperecogênicas, a maior com 9,3 $\mathrm{mm}$ e formadoras de sombreamento acústico posterior, imagens ultrassonográficas que podem estar relacionadas com processo inflamatório (cistite) e urolitos vesicais (Figura 4C).

O rim esquerdo e os demais órgãos não citados apresentavam-se dentro dos parâmetros de normalidade. Ao início, o animal foi tratado com trilostano ${ }^{\underline{g}}(1,5 \mathrm{mg}$ uma vez ao dia), a qual apresentou reação adversa e substituído por melatonina ${ }^{\mathrm{h}}$ ( $3 \mathrm{mg}$ duas vezes ao dia) e dieta padronizada. Houve diminuição do peso e acréscimo de $\mathrm{L}$-carnitina ${ }^{\mathrm{i}}(0,125 \mathrm{mg} / \mathrm{ml} \mathrm{uma} \mathrm{vez} \mathrm{ao} \mathrm{dia).}$ Nas consultas posteriores houve diminuição de $300 \mathrm{~g}$ na primeira e $600 \mathrm{~g}$ na segunda. Foram realizados novos testes de estimulação em que houve diminuição da fosfatase alcalina $560 \mathrm{UI} / \mathrm{L}$; 
triglicerídeos $635 \mathrm{mg} / \mathrm{dl}$, e colesterol de $272 \mathrm{mg} / \mathrm{dl}$. O teste de estimulação foi de 19,8 . Foi reiniciado o tratamento com melatonina ( $3 \mathrm{mg}$ três vezes ao dia).

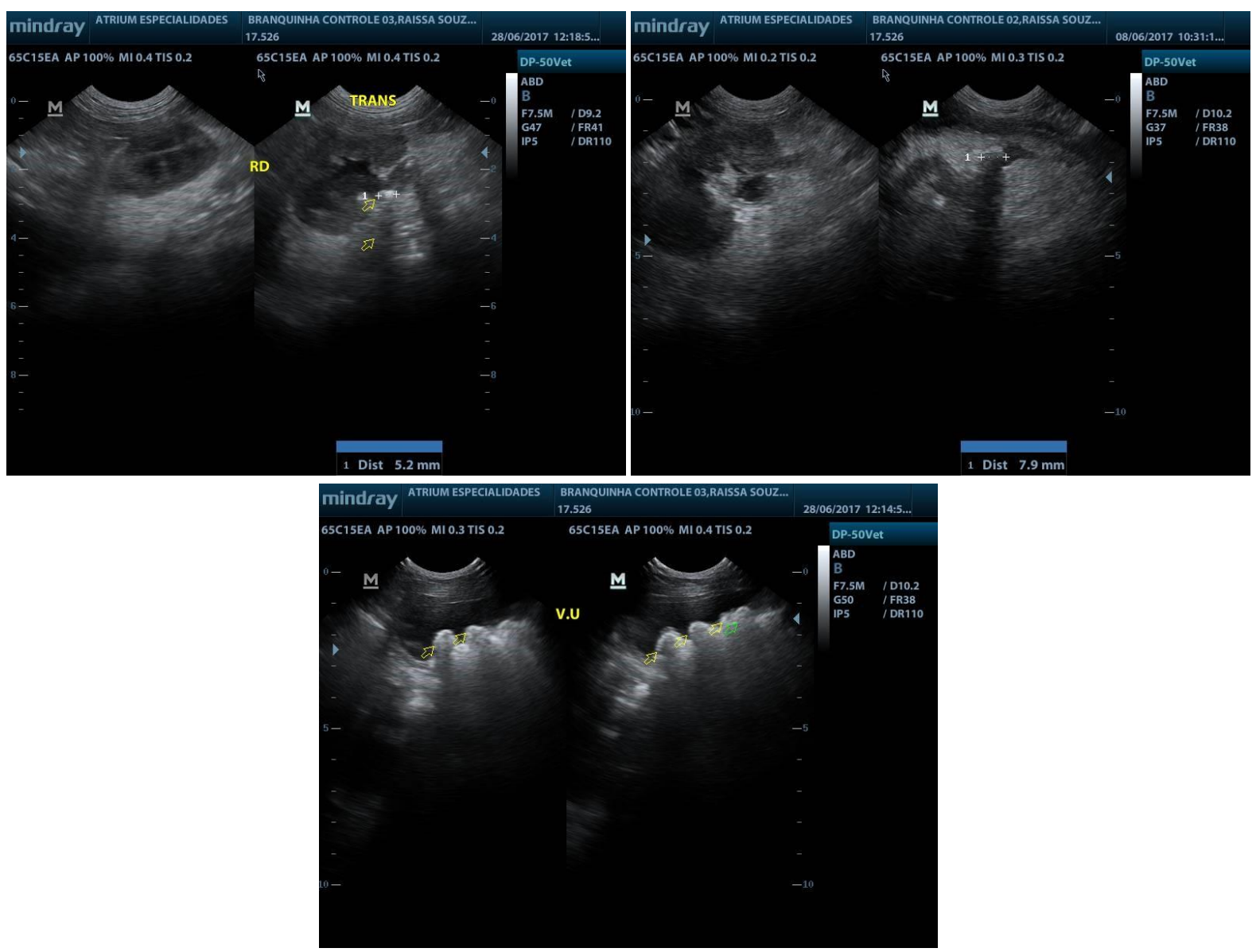

Figura 4. Exame ultrassonográfico realizado em uma cadela da raça Bichon frisé, de 11 anos de idade e 14,6 kg. Observa-se Rim direito com hidroureter e hidronefrose $(\mathbf{A}$ e B) e vesícula urinaria com presença de concreções $(\mathbf{C})$.

Após um mês, a paciente, retorna a clínica veterinária com quadro de apática e fortes dores na palpação abdominal. Na urinálise onde se notou $\mathrm{pH}=9$ (alcalino), proteinúria, sangue oculto e presença de bactérias e muco. No exame ultrassonográfico, que se constataram as mesmas alterações do primeiro, no entanto apresentou dilatação em região de ureter e hidronefrose pouco mais acentuadas.

No pós-operatório não houve nenhum transtorno, o animal foi tratado com amoxicilina ${ }^{j}$, na dose de $20 \mathrm{mg} / \mathrm{kg}$, durante 15 dias. Após esses 15 dias, o animal retornou para a retirada dos pontos.

Aproximadamente um mês depois a paciente retornou a clínica veterinária para ser reavaliada, que por meio de exame ultrassonográfico (Figura 5) e radiográfico (Figura 6). Constatou-se a presença dos cateteres retrouretrocópico e eliminação dos urólitos.

A urolitíase é uma alteração clínica significativa e que aparece com frequência em cães (Picavet et al., 2007). Animais de meia-idade e senis apresentam maior taxa do trato superior em relação aos jovens, observada no estudo do presente relato (Picavet et al., 2007).

A raça Bichon Frise possui predisposição para formação de litíase e como a que possui maior frequência na formação de urólitos de estruvita (Osborne et al., 2009).

As infecções do trato urinário também aumentam a ocorrência de urolitíases. Em cadelas, a infecção do trato urinário inferior por bactérias produtoras de urease, como, por exemplo, Staphylococcus intermedius e Proteus mirabilis, torna o $\mathrm{pH}$ da urina mais alcalino, o que favorece a formação dos urólitos de estruvita, como observado neste relato (Kate et al., 2015; Mariano et al., 2018; Nicoli et al., 2012). 


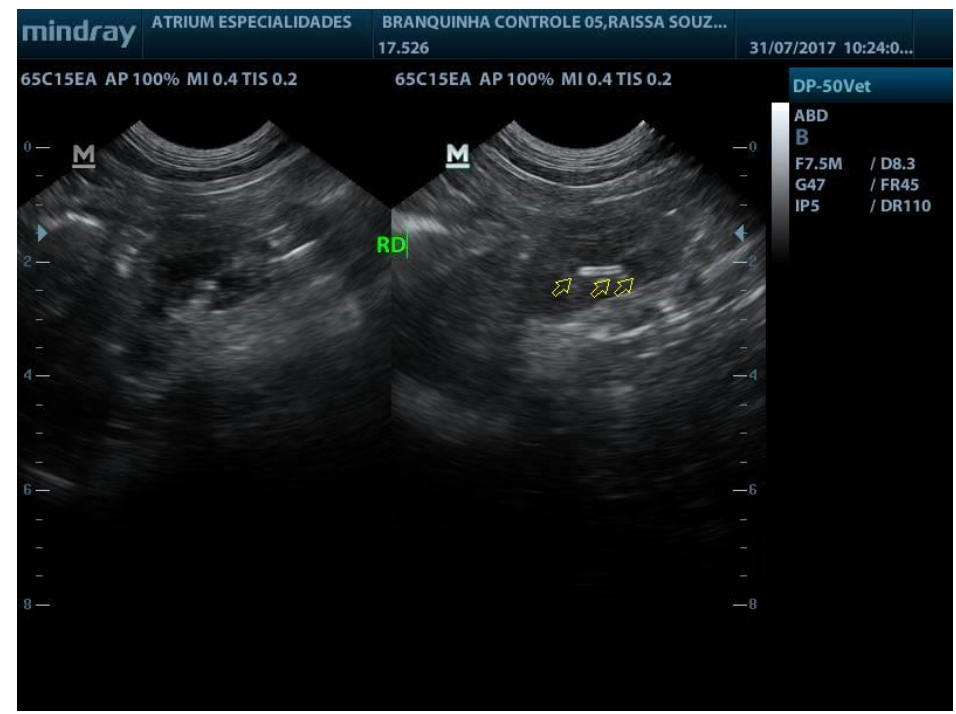

Figura 5. Exame ultrassonográfico realizado em uma cadela da raça Bichon frisé, de 11 anos de idade e 14,6 kg. Observa-se uma linha hiperecogênica o que caracteriza o implante dos cateteres retrouretrocópico.

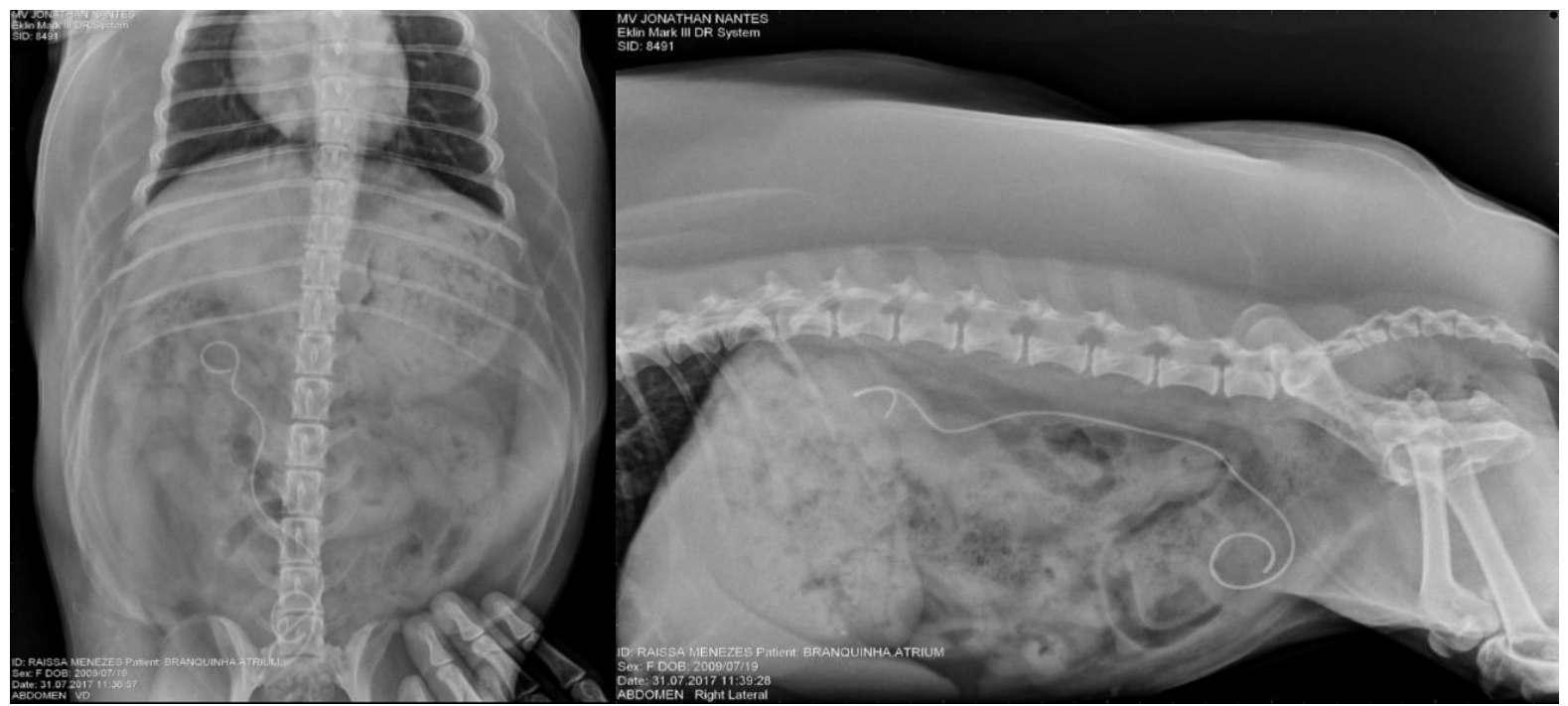

Figura 6. Exames radiográficos realizados em uma cadela da raça Bichon frisé, de 11 anos de idade e 14,6 kg. Observa-se o seguimento radiopaco caracterizado pelo implante de cateter ureterocópico.

Cães com anomalias vasculares portais, hiperparatireoidismo primário, hipercalcemia ou hiperadrenocorticismo são predispostos à formação de os urólitos de oxalato de cálcio e fosfato de cálcio são mais frequentemente encontrados nos casos de hiperadrenocorticismo, em função dos corticoides aumentarem a excreção urinária de cálcio (Nicoli et al., 2012; Tokas et al., 2019). Neste caso, o tutor relatou como queixa principal que o animal apresentava sobrepeso, poliúria, polidpsia e polifagia.

O diagnóstico de hiperadrenocorticismo pode ser confirmado através da realização da dosagem sérica de cortisol pelo teste de estimulação com ACTH ou supressão com baixa ou alta dose de dexametasona (Choo et al., 2018).

Cerca de 95\% dos urólitos localiza-se na uretra ou bexiga (Choo et al., 2018). Menos de 5\% da urolitíase canina são encontrados no rim e ureter (Osborne et al., 2009). Entretanto, neste relato, por auxílio de imagens ultrassonográficas, os urólitos foram localizados na bexiga e ureter proximal ao rim direito mesmo com incidência baixa. Todos os tipos de urólitos, independente das dimensões e da composição, são visibilizados ao exame ultrassonográfico (Mariano et al., 2018).

No cão, o local mais comum de presença de urólitos é na vesícula urinária, por isso, geralmente, nesses casos há sinais clínicos de cistite, como hematúria, polaciúria e disúria. Como observado, a cistite ocorre devido aos urocistólitos agredirem mecanicamente a mucosa, o que desencadeia à erosão, 
ulceração e hemorragia e predispõe à invasão bacteriana da lâmina própria (Tokas et al., 2019). Outras consequências frequentes da obstrução ao fluxo urinário são dilatação vesical, hidroureter e hidronefrose. Essas condições geralmente estão associadas à obstrução parcial ou intermitente ao fluxo urinário (Lulich et al., 2013; Rick et al., 2017). Neste caso, por meio do exame ultrassonográfico os urólitos foram localizados em região de ureter, o que provocou hidroureter, obstrução do fluxo urinário, refluxo da urina e como consequência desenvolveu a hidronefrose.

A urinálise é um exame laboratorial importante para auxiliar no diagnóstico e pode-se observar hematúria, leucocitúria, bacterinúria e células de descamativas, destaca-se que o achado de cristais não é sinônimo da presença de cálculos (Choo et al., 2018) e não corroborado ao quadro do presente relato, em que, notou-se pH alcalino 9, proteinúria, sangue oculto e presença de bactérias e muco.

Os urólitos mais encontrados em cães são os de fosfato amoníaco magnesiano (estruvita) e oxalato de cálcio (Osborne et al., 2009; Picavet et al., 2007). Se observados os casos em que foram comparados os resultados do tipo de mineral que compõe o urólito com o sexo do cão, nota-se o predomínio de fêmeas com cálculos de estruvita (fosfato amoníaco magnesiano) e de machos com cálculos de oxalato de cálcio (Osborne et al., 2009; Picavet et al., 2007). Esta concreção pode ser considerada simples, pois possuem mais de $70 \%$ de sua estrutura composta de apenas um tipo de mineral (Kate et al., 2015). Os urólitos de estruvita são mais prováveis acontecer em casos de urina alcalina (Trevisan et al., 2016). Em sua composição, também foi encontrado $10 \%$ de fosfato de cálcio. E têm como fatores de risco urina alcalina, presença de fosfato na urina, infecções do trato urinário por bactérias produtoras de urease, $\mathrm{o}$ que pode explicar a sua presença na composição (Lulich et al., 2013).

Para o tratamento de urolitiases, pode-se optar por uma terapia médica ou cirúrgica (Osborne et al., 2009). Algumas como estruvita, urato e cistina podem ser passíveis de dissolução com uso de medicações, em pacientes estáveis com mínimo ou nenhum comprometimento renal (Gabriel et al., 2017). Nesse caso, a remoção cirúrgica de cálculos renais e ureterais deve ser considerada, principalmente se eles estiverem infectados ou causarem obstrução (Brustolin, 2017). Contudo, por conta das alterações clínicas significativas que o animal possuía, optou-se pela intervenção cirúrgica. $\mathrm{O}$ emprego de técnicas minimamente invasivas para tratamento de cálculos ureterais é o mais indicado, independentemente da situação. A colocação de stents ureterais é realizada com maior frequência para o tratamento de obstrução ureteral (Grimes et al., 2018). Em que a técnica de escolha para o tratamento do caso relatado, o stents escolhido foi cateter e retrouretrocópico. Os dados baseados em evidência sustentam que os procedimentos e intervenção, como os stents ureterais e a circulação ureteral apresentam menor taxa de morbidade e mortalidade em obstrução ureteral do que as opções cirúrgicas tradicionais em cães e gatos.

Deve-se realizar exames de imagem após tratamento cirúrgico para avaliar se houve remoção completa dos urólitos (Kate et al., 2015). No presente relato foram realizados exames utrassonográficos e radiográficos, para a confirmação completa da remoção das concreções, o que confirma a eficácia do protocolo utilizado. É importante lembrar que, animais com histórico de urolitíase tem uma grande chance de desenvolver recorrência (Picavet et al., 2007). Principalmente se não forem adotadas medidas de manejo em longo prazo e prevenção (Kate et al., 2015).

\section{Conclusões}

Urolitíase é uma afecção relativamente comum na medicina de pequenos animais, e sua incidência aumenta a cada dia. Os principais urólitos encontrados na clínica de pequenos animais são os de estruvita e oxalato de cálcio. O tratamento de eleição é o cirúrgico. Verifica-se que deve ser rapidamente diagnosticada e tratada, pois pode ocorrer da doença se complicar ao seu decorrer e desencadear obstruções urinárias severas. Deste modo, torna-se totalmente indispensável à realização de exame clínico amparado de exames complementares como, radiografia e ultrassonografia, as quais se buscam a possível confirmação de um diagnóstico preciso.

Com base na tolerância prolongada do cateter e poucas complicações registradas em estudos baseados em evidência, o cateter ureteral duplo $\mathrm{J}$ em complicações por cálculos é seguro e efetivo. Mesmo assim, deve-se buscar a etiologia dos urólitos, importante para orientação do tutor nos cuidados que devem ser tomados, como as diversas dietas e medicamentos que serão usados no decorrer do tratamento, proporcionar o bem-estar do animal e qualidade de vida. 


\section{Referências bibliográficas}

Brustolin, D. (2017). Hipospádia canina - relato de caso. Paper presented at the Anais do SEPE Seminário de Ensino, Pesquisa e Extensão.

Choo, M. S., Han, J. H., Kim, J. K., Shin, T. Y., Lee, W. K., Lee, S. K. \& Lee, S. H. (2018). The transgluteal approach to shockwave lithotripsy to treat distal ureter stones: a prospective, randomized, and multicenter study. World journal of urology, 36(8):1299-1306. https://doi.org/10.21037/tau.2018.04.13.

Gabriel W., Marta L. H. C., Rubiele M. V., Rafaela Z. M., Patrícia C. L., Gabriele M., Callegaro S., Vanessa C. B. (2017). Urolitíase em cães e gatos. PUBVET, Medicina Veterinária e Zootecnia, 11(7), 705-714. https://doi.org/10.22256/pubvet.v11n7.705-714

Grimes, J. A., Fletcher, J. M. \& Schmiedt, C. W. (2018). Outcomes in dogs with uroabdomen: 43 cases (2006-2015). Journal of the American Veterinary Medical Association, 252(1):92-97. https://doi.org/10.2460/javma.252.1.92

Kate, E. A., Minter, L. J., Dombrowski, D. S., O'Brien, J. L. \& Lewbart, G. A. (2015). Cystic urolithiasis in captive waxy monkey frogs (Phyllomedusa sauvagii). Journal of Zoo and Wildlife Medicine, 46(1):105-112. https://doi.org/10.1638/2014-0086R1.1

Keihani, S., Anderson, R. E., Fiander, M., McFarland, M. M., Stoddard, G. J., Hotaling, J. M. \& Myers, J. B. (2018). Incidence of urinary extravasation and rate of ureteral stenting after high-grade renal trauma in adults: a meta-analysis. Translational Andrology and Urology, 7(Suppl 2):S169-S178. https://doi.org/10.21037/tau.2018.04.13.

Lulich, J. P., Kruger, J. M., MacLeay, J. M., Merrills, J. M., Paetau-Robinson, I., Albasan, H. \& Osborne, C. A. (2013). Efficacy of two commercially available, low-magnesium, urine-acidifying dry foods for the dissolution of struvite uroliths in cats. Journal of the American Veterinary Medical Association, 243(8):1147-1153. https://doi.org/10.2460/javma.243.8.1147

Mariano, A. D., Penninck, D. G., Sutherland-Smith, J. \& Kudej, R. K. (2018). Ultrasonographic evaluation of the canine urinary bladder following cystotomy for treatment of urolithiasis. Journal of the American Veterinary Medical Association, 252(9):1090-1096. https://doi.org/10.2460/javma.252.9.1090

Nicoli, S., Morello, E., Martano, M., Pisoni, L. \& Buracco, P. (2012). Double-J ureteral stenting in nine cats with ureteral obstruction. The Veterinary Journal, 194(1):60-65. https://doi.org/10.1016/j.tvjl.2012.03.020

Osborne, C. A., Lulich, J. P., Forrester, D. \& Albasan, H. (2009). Paradigm changes in the role of nutrition for the management of canine and feline urolithiasis. Veterinary Clinics of North America: Small Animal Practice, 39(1):127-141. https://doi.org/10.1016/j.cvsm.2008.10.001

Picavet, P., Detilleux, J., Verschuren, S., Sparkes, A., Lulich, J., Osborne, C. A., . . Diez, M. (2007). Analysis of 4495 canine and feline uroliths in the Benelux. A retrospective study: 1994-2004. Journal of animal physiology and Animal Nutrition, 91(5-6):247-251. https://doi.org/10.1111/j.1439-0396.2007.00699.x

Rick, G. W., Conrad, M. L. H., Vargas, R. M., Machado, R. Z., Lang, P. C., Serafini, G. M. C. \& Bones, V. C. (2017). Urolitíase em cães e gatos. PUBVET, 11646-743. https://doi.org/10.22256/pubvet.v11n7.705-714

Tokas, T., Herrmann, T. R. W., Skolarikos, A. \& Nagele, U. (2019). Pressure matters: intrarenal pressures during normal and pathological conditions, and impact of increased values to renal physiology. World Journal of Urology, 37(1):125-131. https://doi.org/10.1007/s00345-018-2378-4.

Trevisan, L. F. A., Sousa, R. V., Bertolucci, S. K. V. \& Rodrigues, O. G. (2016). Alternative treatment in cats affected by FLUTD. Arquivo Brasileiro de Medicina Veterinária e Zootecnia, 68(4):10991103.

Recebido: 16 de maio, 2019.

Aprovado: 15 de junho, 2019.

Publicado: 29 de julho, 2019.

Licenciamento: Este artigo é publicado na modalidade Acesso Aberto sob a licença Creative Commons Atribuição 4.0 (CC-BY 4.0), a qual permite uso irrestrito, distribuição, reprodução em qualquer meio, desde que o autor e a fonte sejam devidamente creditados. 


\section{Produtos utilizados}

a) Dimorf ${ }^{\circledR}$. Cristália Prod. Quím. Farm. Ltda. Itapira, SP, Brasil

b) Propofol ${ }^{\circledR}$. Biossintética. São Paulo, SP, Brasil

c) Isoflurano ${ }^{\circledR}$. Instituto BioChimico Indústria Farmacêutica Ltda. Rio de Janeiro, RJ, Brasil

d) Cedur ${ }^{\circledR}$. Glenmark Farmacêutica Ltda. São Paulo, SP, Brasil

e) Centrum ${ }^{\circledR}$. Laboratório Farmacêutico Vitamed Ltda. Caxias do Sul, RS, Brasil

f) Ômega 3. Laboratório Farmacêutico Vitamed Ltda. Caxias do Sul, RS, Brasil

g) Vetoryl ${ }^{\circledR}$. Vetpharma. Pelotas, RS, Brasil

h) Circadin ${ }^{\circledR}$. RAD Neurim Pharmaceuticals EEC Limited. One Forbury Square, The Forbury, Reading, Berkshire RG1, 3EB - Reino Unido.

i) Levocarnin ${ }^{\circledR}$. Laboratório Farmacêutico Vitamed Ltda. Caxias do Su, RS, Brasil

j) Amoxicilina ${ }^{\circledR}$. Biosintética Farmacêutica Ltda. São Paulo, SP, Brasil 